\title{
Positive selection within the genomes of SARS-CoV-2 and other Coronaviruses independent of impact on protein function
}

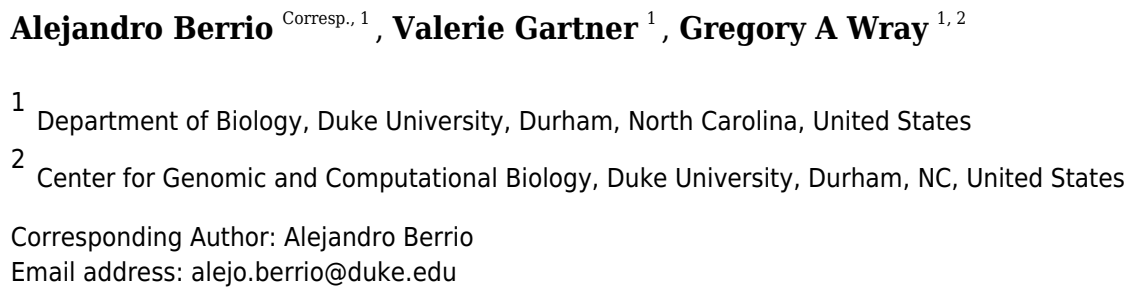

Background. The emergence of a novel coronavirus (SARS-CoV-2) associated with severe acute respiratory disease (COVID-19) has prompted efforts to understand the genetic basis for its unique characteristics and its jump from non-primate hosts to humans. Tests for positive selection can identify apparently nonrandom patterns of mutation accumulation within genomes, highlighting regions where molecular function may have changed during the origin of a species. Several recent studies of the SARS-CoV-2 genome have identified signals of conservation and positive selection within the gene encoding Spike protein based on the ratio of synonymous to nonsynonymous substitution. Such tests cannot, however, detect changes in the function of RNA molecules. Methods. Here we apply a test for branch-specific oversubstitution of mutations within narrow windows of the genome without reference to the genetic code. Results. We recapitulate the finding that the gene encoding Spike protein has been a target of both purifying and positive selection. In addition, we find other likely targets of positive selection within the genome of SARSCoV-2, specifically within the genes encoding Nsp4 and Nsp16. Homology-directed modeling indicates no change in either Nsp4 or Nsp16 protein structure relative to the most recent common ancestor. These SARS-CoV-2-specific mutations may affect molecular processes mediated by the positive or negative RNA molecules, including transcription, translation, RNA stability, and evasion of the host innate immune system. Our results highlight the importance of considering mutations in viral genomes not only from the perspective of their impact on protein structure, but also how they may impact other molecular processes critical to the viral life cycle. 


\section{Positive selection within the genomes of SARS-CoV-2 and other}

2 Coronaviruses independent of impact on protein function

3

4

5 Alejandro Berrio ${ }^{1}$, Valerie Gartner ${ }^{1}$, Gregory A Wray ${ }^{1,2}$

6

7

8 United States

Corresponding Author:

Alejandro Berrio ${ }^{1}$

130 Science Drive, Durham, North Carolina, 27708, United States

Email address: alejo.berrio@duke.edu

\section{Abstract} windows of the genome without reference to the genetic code.

${ }^{1}$ Department of Biology, Duke University, Durham, North Carolina, United States

${ }^{2}$ Center for Genomic and Computational Biology, Duke University, Durham, North Carolina,

Background. The emergence of a novel coronavirus (SARS-CoV-2) associated with severe acute respiratory disease (COVID-19) has prompted efforts to understand the genetic basis for its unique characteristics and its jump from non-primate hosts to humans. Tests for positive selection can identify apparently nonrandom patterns of mutation accumulation within genomes, highlighting regions where molecular function may have changed during the origin of a species. Several recent studies of the SARS-CoV-2 genome have identified signals of conservation and positive selection within the gene encoding Spike protein based on the ratio of synonymous to nonsynonymous substitution. Such tests cannot, however, detect changes in the function of RNA molecules.

Methods. Here we apply a test for branch-specific oversubstitution of mutations within narrow

Results. We recapitulate the finding that the gene encoding Spike protein has been a target of both purifying and positive selection. In addition, we find other likely targets of positive selection 
32 within the genome of SARS-CoV-2, specifically within the genes encoding Nsp4 and Nsp16.

33 Homology-directed modeling indicates no change in either Nsp4 or Nsp16 protein structure 34 relative to the most recent common ancestor. These SARS-CoV-2-specific mutations may affect 35 molecular processes mediated by the positive or negative RNA molecules, including transcription, 36 translation, RNA stability, and evasion of the host innate immune system. Our results highlight 37 the importance of considering mutations in viral genomes not only from the perspective of their 38 impact on protein structure, but also how they may impact other molecular processes critical to the 39 viral life cycle.

\section{Introduction}

42 An important challenge in understanding zoonotic events is identifying the genetic changes that 43 allow a pathogen to infect a new host. Such information can highlight molecular processes in 44 both the pathogen and host that have practical value. The recent outbreak of SARS-CoV-2, a 45 46 novel coronavirus, provides both a challenge and an opportunity to learn more about the specific adaptations that enable the virus to thrive in human hosts and that endow it with traits distinct from previously described coronaviruses (Andersen et al., 2020; Morens et al., 2020). Formal tests for natural selection are a powerful tool in this endeavor because they can be applied in an unbiased manner throughout the viral genome: evidence of negative selection can reveal regions of the genome that are broadly constrained functionally and thus unlikely to contribute to species-specific traits, while evidence of branch-specific positive selection can identify candidate regions of the genome where molecular processes may have diverged from that of other species. Several recent studies have tested for natural selection in the SARS-CoV-2 genome based on the ratio of synonymous to non-synonymous $(\mathrm{dN} / \mathrm{dS})$ substitutions relative to other coronaviruses (Tang et al., 2020; Chaw et al., 2020; Li et al., 2020a). The most prominent signal to emerge from these studies is a mix of positive and purifying selection within the gene encoding the Spike glycoprotein, which mediates invasion of host cells by binding to the angiotensin-converting enzyme 2 (ACE2) receptor in host cells (Gallagher \& Buchmeier, 2001; Tortorici \& Veesler, 2019). This finding makes good biological sense, because structural changes in the spike protein are common and are known to influence the ability of the virus to infect new hosts and jump between species (Hulswit, de Haan \& Bosch, 2016). A single nucleotide polymorphism (SNP) that results in an amino acid substitution in Spike protein ( $>$ G at 23,403 bp; D614G) has 
63 increased in frequency during the global pandemic more rapidly than other SNPs (Korber et al., 64 2020), leading to speculation that it is an adaptation that alters the interaction between Spike and 65 ACE2, FURIN and TMPRSS2 (Eaaswarkhanth, Al Madhoun \& Al-Mulla, 2020).

66 Beyond mutations that alter Spike protein, however, there exists little understanding of positive 67 selection within the SARS-CoV-2 genome and how this may have shaped viral traits. Few convincing signals of positive selection exist for any of the other viral proteins (Cagliani et al., 2020; Velazquez-Salinas et al., 2020; Chaw et al., 2020). For RNA viruses, however, critical aspects of the life cycle rely on molecular processes that are not reflected in protein sequence. In particular, in positive-strand RNA viruses such as coronaviruses, the single RNA molecule that constitutes the genome is first transcribed and translated to produce the replicase polyprotein 1a and $1 \mathrm{ab}$ that is cleaved into multiple non-structural proteins, some of which participate in the assembly of a cellular structure known as the replicase-transcriptase complex (RTC), where the proper environment for viral replication and transcription is created. Then, the RNA-dependentRNA-polymerase (RdRp or Nsp12) produces negative sense genomic and subgenomic RNAs that are used as template strands that are then transcribed in the opposite direction to make more positive-sense viral genomes and a variety of RNA molecules that are translated into structural proteins for packaging (Fehr \& Perlman, 2015; Kim et al., 2020). Although the viral proteins that help mediate these processes are visible to tests for selection that rely on $\mathrm{dN} / \mathrm{dS}$ ratios, the RNA molecules with which they interact are not. This leaves the operation of natural selection on important molecular functions within the viral life cycle largely unexamined.

In order to test for positive selection on RNA function independent of its role in coding for amino acids, we utilized a test for positive selection, adaptiPhy (Berrio, Haygood \& Wray, 2020), that identifies an excess of nucleotide substitutions within a defined window in the genome relative to neutral expectation using a likelihood ratio framework (Wong \& Nielsen, 2004; Haygood et al., 2007). This test infers regions of the genome that were likely targets of branch-specific positive selection in several Sarbecovirus species from bat, pangolin, and human hosts. Our results recapitulate results from $\mathrm{dN} / \mathrm{dS}$-based tests that highlight $S$, the gene encoding Spike protein, as a prominent target of natural selection within the SARS-CoV-2 genome (Cagliani et al., 2020; Chaw et al., 2020; Li et al., 2020a). Importantly, we also identify genomic regions not previously reported to be targets of positive selection. Based on structural modeling 
94 of RNA and protein, we argue that these newly identified regions of positive selection may affect

95 species-specific RNA, rather than protein, function. These genomic regions are candidates for

96 understanding the molecular mechanisms that endow SARS-CoV-2 with some of its unique

97 biological properties.

\section{Materials \& Methods}

\section{Sequence Alignment}

100 To identify branch specific positive selection, it is necessary to obtain a query and a reference

101 alignment. We downloaded six high quality reference genomes from the subgenus Sarbecovirus

102 (Table 1). Next, we used MAFFT (Katoh \& Standley, 2013) plugin in Geneious Prime v.2.1

103 (Kearse et al., 2012) with default settings to build a sequence alignment. Next, we refined the

104 alignment using a gene by gene procedure. More specifically, each coding sequence annotation

105 (i.e. ORF1a, ORF1b, ORF3a, S, M, N, etc) is selected and realigned using the Realign Region

106 tool implemented in Geneious Prime v.2.1 (Kearse et al., 2012) using the MAFFT (Katoh \&

107 Standley, 2013) option.

108

109 Testing for Positive Selection

110 Although adaptiPhy was originally designed to investigate regions of complex genomes under

111 positive selection, it can be used to identify regions of a viral sequence alignment where the

112 foreground branch is evolving at faster rates than the expectation from the background species.

113 We performed a selection analysis on sliding windows of $300 \mathrm{bp}$ with a step of $150 \mathrm{bp}$ along a

114 sequence alignment of 5 reference genome sequences of coronaviruses of the subgenus

115 Sarbecovirus and two sequences of Pangolin Coronavirus recently published (Liu, Chen \& Chen,

116 2019; Lam et al., 2020). This procedure generates partitions where a tree topology can be fitted.

117 To investigate the extent of positive selection or branches with long substitution rates along the

118 SARS-CoV-2 genome, we used a branch-specific method known as adaptiPhy that was initially

119 developed in 2007 (Haygood et al., 2007) and recently improved (Berrio, Haygood \& Wray,

120 2020). This computational methodology makes use of a likelihood ratio test based on the

121 maximum likelihood estimates obtained from HyPhy v2.5 (Pond, Frost \& Muse, 2005; Pond et

122 al., 2020). The branch of interest (e.g., SARS-CoV-2 branch) is used as the foreground and the

123 rest of the alignment is used as the background. To obtain data from nucleotide substitutions

124 alone, we used msa_split from PHAST (Hubisz, Pollard \& Siepel, 2011) to remove insertions 
125

126

127

128

129

130

131

132

133

134

135

136

137

138

139

140

141

142

143

144

145

146

147

148

149

150

151

152

153

154

and any sequence gaps that were present in the genomes of the background virus species relative to the SARS-CoV-2 genome. The assumption for the background species is the same for both the null and alternative models; specifically, only neutral evolution and negative (purifying) selection are permitted. While in the foreground, the assumptions are the same as for the background in the null model. In the alternative model, all three types of evolution are permitted (neutral evolution, negative selection, and positive selection) in the foreground of the following topology: (((((SARS_CoV_2, Bat_CoV_RaTG13), Pa_CoV_Guangdong),

Pa_CoV_Guangxi_P4L), (Bat_CoV_LYRa11, SARS_CoV)), Bat_CoV_BM48). This method is highly sensitive and specific and can differentiate between positive selection and relaxation of constraint (Berrio et al. 2020). AdaptiPhy requires at least $3 \mathrm{~kb}$ reference alignment for each species that is used as a putatively neutral proxy for computing substitution rates. Viruses' genomes lack non-functional regions, therefore, the most reasonable proxy for neutral evolution has to be found in the regions outside the query window. To do this, we concatenated twenty regions of $300 \mathrm{bp}$ of the viral genome alignment that were drawn randomly with replacement from the entire genome alignment. Then, for each query alignment, we built a reference alignment of $6 \mathrm{~kb}$ as it produces a stable evolutionary standard of recombination rates. To control for the stochasticity of the evolutionary process, we run each query against ten bootstrapped samples of reference alignments. Finally, we used a custom R script to compute the likelihood ratio, which was used as a test statistic for a chi-squared test with one degree of freedom to calculate a $P$-value for each query. Then, we corrected the distribution of all $P$-values per query region using the p.adjust() $\mathrm{R}$ function with the fdr method. Next, we classified a query window to be under positive selection if the $P$-adjusted value was $<0.05$. We were unable to successfully run adaptiPhy on two windows because the outgroup species (Bat_CoV_BM48) contained a deletion of 406 bp relative to SARS-CoV-2, which spans the entire ORF8.

To visualize the strength of selection comprehensively, we computed the statistic $\zeta$ (zeta), representing the evolutionary rate. To calculate this rate, we compared the substitution rate in the query with their respective reference alignments. The distribution of substitution rates for each branch and nodes in each query and reference sequence was calculated using phyloFit (Hubisz, Pollard \& Siepel, 2011). Then, the ratio of substitution rate in the query is divided by the substitution rate in the reference. This parameter, " $\zeta$ ", is analogous to $\omega$ (omega), the ratio of 
$155 \mathrm{dN} / \mathrm{dS}$, where a value of $\omega<1$ indicates constraint or negative selection; a value of $\omega=1$ indicates

156 neutrality; and a value of $\omega>1$ indicates positive selection (Wong \& Nielsen, 2004).

157 Testing for Conservation

158 To test for conservation, we used the phastCons computational method from PHAST (Siepel et 159 al., 2005; Hubisz, Pollard \& Siepel, 2011). To run this tool, we used the models obtained with 160 phyloFit for the reference alignments and then, we generated an average estimate of the 161 conserved and non-conserved states of the models with phyloBoot (Hubisz, Pollard \& Siepel, 162 2011). Finally, we run the final analysis using phastCons on the query alignments using the 163 previous models to generate phastCons values for each base-pair along the sequence. To plot

164 these we took the average from each alignment and plot it using the library Gviz and

165 Bioconductor (Hahne \& Ivanek, 2016) in R.

166 Testing for Recombination

167 Inference of branch specific selection can be confounded by recombination given that a single 168 phylogenetic tree may not explain the evolution of viruses. Recombination is common in 169 coronaviruses (Hon et al., 2008; Graham \& Baric, 2010; Lau et al., 2015; Hu et al., 2017; Li et 170 al., 2020b; Lam et al., 2020) and it should be accounted for as an alternative explanation of 171 selection at the nucleotide level. Here, we screened for evidence of recombination by estimating 172 phylogenetic trees in sliding windows of $500 \mathrm{bp}$ and a step of 150 along coronavirus alignment 173 using RaXML-NG v0.9 (Kozlov et al., 2019).

\section{Evaluating polymorphic diversity in the pandemics of 2020}

175 We downloaded complete sequences of SARS-CoV-2 genomes from the NCBI Virus database 176 (https://www.ncbi.nlm.nih.gov/labs/virus/vssi/\#/virus?SeqType_s=Nucleotide). As of June 26, 177 2020, we obtained and aligned 5597 SARS-CoV-2 genomes sequenced worldwide. To align 178 these sequences, we used MAFFT (Katoh \& Standley, 2013) plugin from Geneious Prime 2.1 179 (Kearse et al., 2012), eliminating 597 sequences with the highest number of differences and 180 ambiguities relative to the reference sequence (RefSeq: NC_045512.2), for a total of 5,000 181 sequences. Next, we estimated the frequency of SNP variants using the Find Variations/SNPs 182 tool with a minimum coverage of 4,900 sequences and a minimum frequency of 0.01 , to identify 183 nucleotide variants among a subset of high quality sequenced genomes in order to evaluate 184 ongoing evolution in the regions under positive selection. 
186 To investigate potential structural changes in Nsp4 and Nsp16 at both the RNA and protein level, 187 we performed minimum free energy (MFE) prediction analysis using the RNAfold WebServer 188 (Gruber et al., 2008; Lorenz et al., 2011) and consensus homology modeling using PHYRE2's

189

190

191

192

193

194

195

196

197

198

199

200

201

202

203

204

205

206

207

208

209

210

211

212

213

214

215

216 intensive mode (Kelley et al., 2016). These analyses were performed for both Nsp4 and Nsp16 sequences for SARS-CoV-2, Bat-CoV_RaTG13, Pan-CoV-Guangdong, and SARS-CoV. RNAfold uses a loop-based energy model and a dynamic programming algorithm to predict the structure of the sequence such that the free energy of the structure is minimized. The RNAfold WebServer generates graphical outputs for both the MFE and Centroid structures, which display the base pairing probabilities by color $($ blue $=0$, red $=1$ ). These two MFE structures correspond to the MFE and the Centroid traces in the mountain plot, which is a positional representation of the secondary structure. In our figures, we show the MFE structure prediction.

PHYRE2 aligns input protein sequences using Position-Specific Iterated BLAST (PSI-BLAST) against sequences of experimentally resolved protein structures. A 3D model of the input sequence is then constructed based on homology-matched templates, optimizing for greatest sequence coverage and highest confidence. Regions of the input sequence without a matching template sequence are modeled $a b$ initio and with Poing, a multi-template modelling tool. Pairwise comparisons of predicted protein structures were visualized using PyMOL software (DeLano, 2002). Alignment and structural comparisons performed by FATCAT (Ye \& Godzik, 2004).

\section{Results}

\section{Positive and negative selection are highly localized within coronavirus genomes}

We tested for branch-specific selection on nucleotide sequences in coronavirus genomes, focusing on six species from the Sarbecovirus Subgenus (Coronaviridae family) and Bat-CoVBM48-31/BGR/2008 as an outgroup. Using $300 \mathrm{bp}$ windows with a step size of $150 \mathrm{bp}$, we scanned the genome alignment for concentrations of fixed mutations that exceed the neutral expectation based on the genome as whole relative to that particular window's evolutionary history among the seven species. This test identifies regions of the genome showing the most extreme divergence in nucleotide sequence on a particular branch relative to its specific background rate of evolution across the entire phylogeny and without reference to the genetic code. Fig 1A shows windows of inferred positive selection (red dots) on the branch leading to each species. The results reveal several signals of positive selection that are unique to a single 
217 species and others that are recapitulated in multiple species. The latter finding suggests that some 218 segments of the viral genome have repeatedly experienced adaptive modification. In general, the 219 distribution of positive selection is more similar in closely related species than in divergent ones 220 (Figs 1A and 1B), suggesting that some molecular functions have been altered over an interval

221

222

223

224

225

226

227

228

229

230

231

232

233

234

235

236

237

238

239

240

241 242 species.

243

244

245

246

247 radiation. that extends beyond the origin of a single species but not across the entire Sarbecovirus

Next, we identified regions of the genome that are highly conserved across the Sarbecovirus genomes examined in this study using PhastCons (Siepel et al., 2005) (Fig 2A). As with positive selection, conservation is highly localized (Figs 2A and 2B). Based on a criterion of PhastCons $>$ 0.9, we found high levels of conservation in regions encoding seven proteins: 3CL-Pro, Nsp6, Nsp8, Nsp9, Nsp10, Nsp11, RdRp, ORF3a (Protein 3a), Nucleocapsid phosphoprotein (NC), and Envelope (E) (Figs 2A-D). These loci of exceptional sequence conservation highlight critical molecular features: $\mathrm{NC}$ and $\mathrm{E}$ are essential structural proteins of the coronavirus capsid, while the other proteins regulate a variety of molecular process during viral replication (Tan et al., 2005; Lu et al., 2006; Minakshi et al., 2009; Freundt et al., 2010; Fuchs, 2012; Yue et al., 2018). Because new mutations emerge and new strains replace older ones, we next investigated how much the specific strain used to represent SARS-CoV-2 influences test results. We re-ran the tests for positive selection using a strain of SARS-CoV-2 that contains four derived SNPs that commonly co-occur in currently circulating strains. Using this strain did not change the distribution of inferred regions of positive selection during the origin of SARS-CoV-2 (S6 Fig).

We also generated two artificial genomes where we added four and nine mutations in the vicinity of site 14,408 to test the sensitivity of the test. We found that as zeta increased within the window, the test turned significant when more than five mutations are added (S1 Fig). It is important to note that the exact number of mutations that produce a significant test result may differ in other regions of the genome, depending on the degree of sequence conservation among

\section{The gene encoding Spike protein is under persistent positive selection}

In all ingroup species examined we detected signals of positive selection within the $\mathrm{S}$ gene, which encodes the Spike protein. With the exception of Pa-CoV-Gx, this was the most prominent signal in the entire genome (Fig 1A). This finding confirms previous studies that used 
248 the dN/dS ratio to test for selection on protein function (Tang et al., 2020; Chaw et al., 2020; Li

249 et al., 2020a). Interestingly, we observed that the specific regions showing signatures of positive 250 selection differed between species (Figs 1B and 1C). In SARS-CoV-2, we detected signals of 251 positive selection in four segments of the $\mathrm{S}$ gene. First, the region encoding the entire receptor 252 binding domain (RBD) shows an extended signal (Figs 1B-C and 3A); as others have noted, 253 structural changes in this region may improve binding to human ACE2 (Wang et al., 2020; 254 Wrapp et al., 2020; Wang, Liu \& Gao, 2020). The second segment encodes another externally 255 facing region, the S1 subunit N-terminal (NTD) domain, which includes the first disulfide bond 256 (amino acids 13 - 113) and several glycosylation sites. The third signal of positive selection 257 within $\mathrm{S}$ is located around the derived furin cleavage site (amino acids $664-812$ ) that has been 258 found to be essential for infection of lung cells (Hoffmann, Kleine-Weber \& Pöhlmann, 2020). 259 The fourth signal is located in a segment encoding the S2 and S2' subunits that includes the 260 Heptad repeat 2 (amino acids 1114 - 1213). These heptad repeats were previously associated 261 with episodes of selection for amino acids that increase the stability of the six-helix bundle 262 formed by both heptad repeats in MERS and other coronaviruses (Forni et al., 2015); they are 263 also thought to determine host expansions and therefore, facilitate virus cross-species 264 transmission (Graham \& Baric, 2010).

265 The distribution of inferred positive selection in the S gene of SARS-CoV differed from that of 266 SARS-CoV-2 described above. Notably, there was no signal in the ACE2 binding domain (Figs 267 1B and 1C). Moreover, a signal was present throughout the N-terminal domain and in the 268 boundary region between the S1 and the S2 subunits (Fig 1), a region that includes the 269 proteolytic cleavage (M de Haan et al., 2004). Interestingly, this region evolved a novel furin 270 cleavage site in SARS-CoV-2 that may increase the cleavage efficiency and cell-cell fusion 271 activity and changes in the virulence of the virion as seen in mutant studies of SARS-CoV and 272 SARS-CoV-2 (Follis, York \& Nunberg, 2006; Hoffmann, Kleine-Weber \& Pöhlmann, 2020). 273

274 Genes encoding Nsp4 and Nsp16 contain branch-specific signals of positive selection 275 We also detected two shorter signals of positive selection within the SARS-CoV-2 276 genome that are located outside of the $\mathrm{S}$ gene, in pplab and ppla (Fig 1A). Interestingly, both 277 encode small proteins that contribute to viral replication. The first is Nsp4, which encodes a 278 membrane-bound protein with a cytoplasmic C-terminal domain; it is thought to anchor the 
279 Viral-Replication-Transcription Complex (RTC) to the modified endoplasmic reticulum 280 membranes in the host cell (Oostra et al., 2008; Hagemeijer et al., 2011, 2014; Snijder, Decroly $281 \&$ Ziebuhr, 2016). The SARS-CoV-2 Nsp4 protein differs from that of closely related 282 sarbecoviruses by two nearly adjacent amino acids: V380A and V382I. Although this region of 283 the genome as a whole is not highly conserved (Fig 2), both of these positions are V residues in 284 all of the in-group species we examined except SARS-CoV-2 (Fig 3B and S2A). This signal is 285 too weak to be scored as positive selection using dN/dS-based tests (Tang et al., 2020; Chaw et 286 al., 2020; Li et al., 2020a) and indeed may not affect protein function given the biochemically 287 similar side-chains of the amino acids involved.

288 The second signal of positive selection outside of the S gene lies within Nsp16. This gene 289 encodes a 2'-O-methyltransferase that modifies the 5'-cap of viral mRNAs (Decroly et al., 2008; 290 Bouvet et al., 2010) and assists in evasion of the innate immune system of host cells (Züst et al., 291 2011; Menachery, Debbink \& Baric, 2014; Nelemans \& Kikkert, 2019). Of note, this is the only 292 signal of positive selection within the SARS-CoV-2 genome that lacks any nonsynonymous 293 substitutions (Fig 3C), and thus could not have been detected by any test that relies on the dN/dS 294 ratio. All of the nucleotide substitutions in Nsp16 during the origin of SARS-CoV-2 are synonymous, while the Nsp16 genes of SARS-CoV-2, Bat-Cov-RaTG13, and Pan-CoV-GD (Guangdong) all encode identical proteins (Figs 3C and S3A). This suggests a complex mechanism of selection in the form of purifying selection at the protein level and branch-specific positive selection at the nucleotide level. Ancestral state reconstruction of Nsp16 indicates that 20 synonymous substitutions likely occurred in the lineage leading to SARS-CoV-2 after the split from the common ancestor with BatCoV-RaTG13, while 19 substitutions are synonymous substitutions that occurred in the lineage leading to Bat-CoV-RaTG13 (Supplementary Data). Eleven of these twenty substitutions are concentrated within the region scoring high for positive selection in SARS-CoV-2 and twelve within the positively selected region in Bat-CoV-RaTG13. 304

As a consequence, we hypothesized that the Nsp16 RNA secondary structure may differ among 306 species in ways that affect molecular functions mediated directly (although not solely) by RNA, such as replication, transcription, translation, or evasion of the host immune system. To investigate this possibility, we first compared the secondary structure and minimum free energy 
310 CoV-RaTG13, Pan-CoV-GD, and SARS-CoV using RNAfold (Gruber et al., 2008). Both the

311 predicted secondary structures and mountain plots, which show the free energy predictions along

312 the length of the sequence by position, reveal differences in RNA folding dynamics across the

313 four species (S2B and S3B Figs). Analysis of the reconstructed sequence of the SARS-CoV-2+

314 Bat-CoV-RaTG13 ancestor reveal that most of these differences evolved during the origin of

315 SARS-CoV-2 (S4 Fig). These differences among species in predicted secondary structures

316 within Nsp4 and Nsp16 stand in contrast to the 5' UTR, which is thought to fold into a stable

317 secondary structure that is markedly conserved among Sarbecovirus species (S5 Fig). Though

318 the accuracy of MFE predictions is too low to conclusively determine whether there are real

319 between-species differences in the RNA structures of these loci (Mathews, 2005), these

320 observations suggest that the signal of positive selection within Nsp16 in the SARS-CoV-2

321 genome may reflect changes in RNA, rather than protein, function that are unique to this species

322 of coronavirus.

323 While the focus here is on SARS-CoV-2, it is worth noting that we also detected signals of

324 positive selection outside of the S gene in the other Sarbecovirus genomes examined here. The

325 distribution of positive selection in the genome of SARS-CoV, for instance, shows some

326 similarities to, but also notable differences from, that of SARS-Cov-2 (Fig 1). In both species, S

327 and Nsp16 contain signals of positive selection, although in distinct regions of the two genes (Fig

328 1). In addition, the genome of SARS-CoV contains signals of positive selection in Nsp2, Nsp3,

329 and ORF3a, none of which shows elevated rates of substitution in SARS-CoV-2. The first two

330 genes encode proteins with important roles in viral replication: Nsp2 may disrupt intracellular

331 signaling in the host cell (Cornillez-Ty et al., 2009) while Nsp3 cleaves itself, Nsp1, and Nsp2

332 from the replicase polyproteins (Báez-Santos, St. John \& Mesecar, 2015), assists in the assembly

333 of the double membrane vesicles of the RTC system (Hagemeijer et al., 2014), and antagonizes

334 the host innate immune response (Tsuchida, Kawai \& Akira, 2009; Frieman et al., 2009;

335 Matthews et al., 2014).

336 Recombination does not account for most signals of positive selection

337 Recombination from another species can be a confounding factor in the inference of positive

338 selection using the framework employed here, because the inserted genomic segment may be

339 more divergent than the rest of the foreground genome is from nearby background species.

340 Several instances of recombination have been reported in coronaviruses, including SARS-CoV-2

Peer] reviewing PDF | (2020:09:52881:1:1:NEW 1 Oct 2020) 
341 (Hon et al., 2008; Lam et al., 2020; Boni et al., 2020; Li et al., 2020a), making it important to

342 distinguish regions of recombination from positive selection. The two processes produce distinct

343 genetic signatures, with recombination the result of a single event (possibly later further

344 recombined) and positive selection as detected here the result of multiple independent mutations

345 that were fixed over an extended interval and are spatially concentrated. In order to test for

346 regions of the SARS-CoV-2 that contain recombined segments from other species, we estimated

347 the phylogenetic history of $500 \mathrm{bp}$ segments of the genome with a step size of $150 \mathrm{bp}$ among the

348 aligned genomes of the seven species examined in this study. We used RaXML-NG v0.9

349 (Kozlov et al., 2019) to reconstruct topology for each segment independently and searched for

350 cases where the topology differed from the expected topology based on the entire genome: (Bat-

351 CoV-BM48, ((Bat-CoV-LYRa11, SARS-CoV), (Pa-CoV-GX, (Pa-CoV-GD, (SARS-CoV-2, Ba-

352 CoV-RaTG13)))). Recombination from a divergent species should produce an incongruent

353 topology in one or more adjacent windows, revealing a recombined region and its approximate

354 breakpoints. We identified 12 regions where the topology differed from the expected (Fig 4). Of

355 note, these regions are somewhat more concentrated in the part of the genome that encodes

356 structural proteins. Consistent with a previous report (Li et al., 2020a), we observed overlap

357 between regions scoring high for positive selection and recombination in S, the gene encoding

358 Spike protein (Fig 4M), specifically the region that encodes for the ACE2 binding domain and a

359 region that includes the furin-cleavage site (Figs 4F-G). Importantly, however, none of the

360 putatively recombined regions overlap with the windows scoring high for positive selection

361 within the genes encoding Nsp4 and Nsp16 proteins in SARS-CoV-2.

362 Recent changes in allele frequency may result from positive selection and hitch-hiking

363 To gain insight into the evolutionary mechanisms that have shaped genetic variation more

364 recently within the SARS-CoV-2 genome, we compiled a list of known mutations, based on

3655,000 accessions sequenced since the beginning of the current pandemic (see Methods). As

366 expected, the vast majority of variants are singletons, representing either mutations that are not

367 segregating or sequencing errors. The density distribution of polymorphisms (regardless of

368 frequency) is elevated within 2-3 kb at both ends the SARS-CoV-2 genome (Fig 2D) and the

369 site-frequency spectrum is strongly left-skewed (S6 Fig). 
371 We next investigated the likely consequences for altered molecular function due to each of these

372 four high-frequency derived SNPs. Two are located within regions of the genome that are highly 373 conserved among Sarbecovirus species (Figs 2B-C). The first is a C>U substitution at position 374241 in the 5'UTR, a region of the genome where RNA secondary structure is highly conserved 375 across Coronavirus species (Madhugiri et al., 2016; Rangan et al., 2020; Alhatlani, 2020). Using 376 RNAfold (Gruber et al., 2008) we found that this $\mathrm{C}>\mathrm{U}$ transition had no impact on the stem-loop 377 structure established for SARS-CoV (S5 Fig). The other mutation in a conserved region of the 378 genome is a nonsynonymous substitution in the RdRp gene $(14,408$; P323L) at the interface 379 domain, which is thought to mediate protein-protein interactions (Pachetti et al., 2020; Hillen et 380 al., 2020). Because proline residues can influence secondary structure, we used PHYRE2 to 381 predict the impact of the P232L mutation on protein structure. Comparison of the two predicted 382 structures using FATCAT shows they are nearly identical (Table S1). The other two high383 frequency derived SNPs are located in regions that are neither highly conserved nor highly 384 divergent. One is a synonymous SNP in Nsp3 $(3,037)$ and the other a nonsynonymous SNP in S 385 (23,403; D614G). This last SNP effectively removes a charged side-chain between the receptor 386 binding domain and the furin cleavage site of S, a region of recurrent positive selection among 387 the Sarbecovirus species we examined. Thus, of the four high-frequency derived SNPs, the 388 nonsynonymous substitution in $\mathrm{S}$ the most plausible candidate for altering molecular function 389 and thus becoming a target of natural selection.

390

391 Discussion

392 A crucial feature contributing to the global spread of COVID-19 is that viral shedding starts 393 before the onset of symptoms (He et al., 2020); in contrast, shedding began two to ten days after 394 the onset of symptoms during the SARS epidemic of 2003 (Peiris et al., 2003; Pitzer, Leung \& 395 Lipsitch, 2007). This striking difference suggests that one or more molecular mechanisms during 396 host cell invasion, virus replication, or immune avoidance may have changed during the origin of SARS-CoV-2. Mutations contributing to viral transmission would likely be favored by natural selection, making tests for positive selection a useful tool for identifying candidate genetic changes responsible for the unique properties of SARS-CoV-2. Here, we searched for regions of possible positive selection within the genomes of six coronavirus species, including SARS-CoV and SARS-CoV-2. The method we used tests for an excess of branch-specific nucleotide 
402 substitutions within a defined window relative to a neutral expectation for divergence in that 403 window and without regard to the genetic code (Wong \& Nielsen, 2004; Haygood et al., 2007; 404 Berrio, Haygood \& Wray, 2020).

405 Several prior studies have identified $S$, the gene encoding the Spike glycoprotein, as a target of 406 recurrent positive selection in coronavirus genomes, including SARS-CoV-2, based on $\omega$, the 407 ratio of synonymous to nonsynonymous substitutions (Andersen et al., 2020; Cagliani et al., 408 2020; Tang et al., 2020; Armijos-Jaramillo et al., 2020; Li et al., 2020a). S thus serves as a 409 positive control for our ability to detect signals of positive selection using a different approach, 410 which considers mutations without respect to the genetic code and uses a likelihood ratio 411 framework to identify regions of elevated, branch-specific nucleotide substitution rates relative 412 to a model that allows only drift (Wong \& Nielsen, 2004; Haygood et al., 2007; Berrio, Haygood $413 \&$ Wray, 2020). Consistent with this expectation, we found that portions of the gene encoding 414 Spike showed a striking elevation of sequence divergence relative to the rest of the genome on 415 the branches leading to all six species examined. The specific regions of S containing high 416 divergence differs markedly, however, among species (Fig 1B). In SARS-CoV and Bat-CoV417 LYRa11, these regions include the N-terminal region, which contains glycosylation sites 418 important for viral camouflage (Watanabe et al., 2019; Yang et al., 2020) and a site of proteolytic 419 cleavage that allows entry into the host cell (Belouzard, Chu \& Whittaker, 2009) (Fig 1C and 420 3A). In contrast, signals of positive selection in SARS-CoV-2 and Bat-CoV-RaTG13 are 421 concentrated in the domain that mediates binding to the host receptor ACE2 (Fig 1C and 3A). 422 These distinct distributions suggest that modifications in different aspects of Spike function took 423 place as various coronaviruses adapted to novel hosts. In particular, the concentration of derived 424 amino acid substitutions in the receptor binding domain of Spike (Figs 1B and 1C) in SARS425 CoV-2 and Bat-CoV-RaTG13 may reflect selection for amino acid substitutions that result in 426 higher affinity for ACE2 protein in different host species.

427 Importantly, we also detected signals of positive selection in two additional regions of the 428 SARS-CoV-2 genome, specifically within the genes encoding Nsp4 and Nsp16 (Figs 1A and 429 2A). Of note, the Nsp16 region also shows a parallel signal of positive selection on the branch 430 leading to SARS-CoV. To our knowledge, this is the first report of possible adaptive change in 431 molecular function during the evolutionary origin of SARS-CoV-2 outside of the gene encoding 432 Spike protein. Prior scans for positive selection within the SARS-CoV-2 genome used elevated $\omega$ 
433 as the signal of positive selection, which restricts attention to positive selection based on changes 434 in protein function. For coronaviruses this is a notable limitation, given that many aspects of the 435 lifecycle involve RNA function (Madhugiri et al., 2016; Ziv et al., 2020; Alhatlani, 2020). In 436 addition, the secondary structure of some segments within the RNA genome is well conserved 437 among coronavirus species, which implies a functional role (Rangan et al., 2020; Sanders et al., 438 2020; Huston et al., 2020a). Indeed, the SARS-CoV-2 genome is reported to contain more well439 structured regions than any other known virus, including both coding and noncoding regions of 440 the genome (Huston et al., 2020a). We therefore examined nucleotide substitutions within 441 regions of putative positive selection in Nsp4 and Nsp16 for their likely impact on both protein 442 and RNA structure (S2 and S3 Figs).

443 In the case of Nsp4 protein, two nearly adjacent nonsynonymous substitutions at residues 380 444 and 382 occurred on the branch leading to SARS-CoV-2 (Fig 3B). These both involve changing 445 side chains with similar biochemical properties, respectively valine to alanine and valine to 446 isoleucine. Homology-directed modeling of protein structure suggests that these two amino acid 447 substitutions have very little impact on either secondary or tertiary structure when comparing the 448 SARS-CoV-2 protein orthologue to those of the other species examined (S2A Fig). In the case of 449 Nsp16 protein, no nonsynonymous substitutions evolved on the branch leading to SARS-CoV-2. 450 Thus, the signal of positive selection within Nsp4 is unlikely to reflect changes in protein 451 structure or function, while the signal within Nsp16 cannot affect either because the encoded 452 polypeptide is identical (Fig 3C and S3A Fig).

453 With highly similar and identical protein structures predicted for Nsp4 and Nsp16, respectively, 454 we considered the possibility that the signals of positive selection instead reflect changes in RNA 455 structure and function. Previous studies found that neither the Nsp4 nor Nsp16 regions stand out as particularly well folded regions of the genome, although Nsp16 does contain a single wellfolded region and Nsp4 two moderately well folded regions (Rangan et al., 2020; Huston et al., 2020b). Further, both genes show significantly decreased sequence divergence among coronavirus species within predicted double-stranded region (Rangan et al., 2020; Sanders et al., 460 2020; Huston et al., 2020a). Indeed, the well-folded region within Nsp16 is the only such region in the SARS-CoV-2 genome that is also well conserved among related coronaviruses (Sanders et al., 2020). These published observations suggest possible functional roles for folded structures 463 within Nsp4 and Nsp16. While we have not taken a robust experimental approach to determine 
464 between-species differences in RNA secondary structure, our in silico minimum free energy 465 (MFE) predictions suggest that the likely secondary structure of the RNA genome in the region 466 of the Nsp4 and Nsp16 genes may differ among the six coronavirus species we examined (S2B 467 and S2B Figs, top rows). The MFE predictions also indicate differences among species in 468 entropy across the regions containing the signals of positive selection, indicating possible 469 differences in the stability of the folded molecule (S2B and S3B Figs, bottom rows). Together, 470 these results indicate that the folded regions of Nsp4 and Nsp16 in the SARS-Cov-2 genome 471 may differ in shape from those of related coronaviruses.

472 Unfortunately, little is currently known about the molecular functions of secondary structures in 473 coronavirus genomes. Most of the attention has been directed towards the 5' UTR, 3' UTR, and 474 frameshift element at the junction between ORF1a and ORF1b, which together contain the most 475 well-folded regions in the SARS-CoV-2 genome (Andrews et al., 2020; Sanders et al., 2020; 476 Huston et al., 2020a). Thus, it is not possible at this time to link structural and thermodynamic 477 features within Nsp4 and Nsp16 that are unique to SARS-CoV-2 to specific molecular functions. 478 As discussed above, however, published evidence suggests that RNA secondary structures within 479 these regions of the genome may be functional (Rangan et al., 2020; Sanders et al., 2020; Huston 480 et al., 2020a). These functions could, in principle, affect genome or transcript function, or both.

481 Plausible possibilities include secondary structures that recruit specific RNA-binding proteins to 482 mediate transcriptional regulation or transcript processing (Pirakitikulr et al., 2016; Pan et al., 483 2020), that mediate looping for other reasons (Gebhard, Filomatori \& Gamarnik, 2011; Ziv et al., 484 2020), or that simply facilitate or impede processivity of the replication or translation machinery 485 (MacFadden et al., 2018).

487 To investigate what evolutionary mechanisms are shaping the genetic variation at the population 488 level, we examined known mutations among 5,000 accessions from NCBI. Given that the 489 effective population size of SARS-CoV-2 is likely very large, the alternative allele distribution 490 (S6 Fig) suggests that most SNPs are not subject to positive selection and that negative selection 491 prevents most new mutations from rising in frequency due to drift, although this may change as 492 additional whole genomes are examined. However, we did observe four SNPs that are present at 493 high alternative allele frequency ( $\mathrm{AAF}>0.6)$ (Fig 2C), a situation that can reflect positive 494 selection, drift, or hitch-hiking. Interestingly, all four of these SNPs are in tight LD (Toyoshima 
495 et al., 2020), which suggests that positive selection on one of them may have driven the other 496 three to high frequency due to hitch-hiking. Based on molecular modeling, the high-frequency 497 derived mutation in $\mathrm{S}$ is the most plausible to be under positive selection, while the other three 498 may be elevated due to hitch-hiking.

\section{Conclusions}

500 Scans for positive selection typically focus on changes in protein function and far less often 501 consider the possibility of adaptive change in RNA function. By shining a light on regions of the 502 SARS-CoV-2 genome that appear to be under positive selection yet are unlikely to alter protein 503 function, our results illustrate the value of evaluating the potential for adaptive changes in 504 secondary structures within the genomes of RNA viruses. In particular, we identify Nsp4 and 505 Nsp16 as regions of the SARS-Cov-2 genome that may contain mutations that contribute to the 506 unique biological and epidemiological features of this recently emerged pathogen.

507 While it is tempting to speculate about the possible adaptive role of changes in RNA structure 508 within these accelerated regions, we suggest that this is best done in the context of relevant 509 experimental results. For example, it might be informative to modify the primary sequence of the 510 genome so as to encode the same protein sequence while altering or disrupting secondary 511 structure within Nsp4 or Nsp16, then assay the consequences for viral replication and for specific 512 molecular functions. We hope that our results inspire these or other experiments aimed at better 513 understand the evolving functions of RNA secondary structure within the SARS-CoV-2 genome. 514

\section{Acknowledgements}

516 The authors would like to thank all the members of the lab groups of David McClay and

517 Greg Wray for comments and the Compact for Open-Access Publishing Equity (COPE) program 518 at Duke University for supporting publication costs.

519 


\section{References}

521 Alhatlani BY. 2020. In silico identification of conserved cis -acting RNA elements in the SARS-

522 CoV-2 genome. Future Virology:fvl-2020-0163. DOI: 10.2217/fvl-2020-0163.

523 Andersen KG, Rambaut A, Lipkin WI, Holmes EC, Garry RF. 2020. The proximal origin of

524 SARS-CoV-2. Nature Medicine 26:450-452. DOI: 10.1038/s41591-020-0820-9.

525 Andrews RJ, Peterson JM, Haniff HS, Chen J, Williams C, Grefe M, Disney MD, Moss WN.

526 2020. An in silico map of the SARS-CoV-2 RNA Structurome. bioRxiv : the preprint server

527 for biology:2020.04.17.045161. DOI: 10.1101/2020.04.17.045161.

528 Armijos-Jaramillo V, Yeager J, Muslin C, Perez-Castillo Y. 2020. SARS-CoV-2, an

529 evolutionary perspective of interaction with human ACE2 reveals undiscovered amino acids 530 necessary for complex stability. Evolutionary Applications:eva.12980. DOI:

$531 \quad 10.1111 /$ eva.12980.

532

Báez-Santos YM, St. John SE, Mesecar AD. 2015. The SARS-coronavirus papain-like protease:

533 Structure, function and inhibition by designed antiviral compounds. Antiviral Research

534 115:21-38. DOI: 10.1016/j.antiviral.2014.12.015.

535 Belouzard S, Chu VC, Whittaker GR. 2009. Activation of the SARS coronavirus spike protein

536 via sequential proteolytic cleavage at two distinct sites. Proceedings of the National

537 Academy of Sciences of the United States of America 106:5871-5876. DOI:

$538 \quad 10.1073 /$ pnas.0809524106.

539 Berrio A, Haygood R, Wray GA. 2020. Identifying branch-specific positive selection throughout

540 the regulatory genome using an appropriate proxy neutral. BMC Genomics 21:359. DOI:

$541 \quad 10.1186 / \mathrm{s} 12864-020-6752-4$.

542 Boni MF, Lemey P, Jiang X, Lam TT-Y, Perry BW, Castoe TA, Rambaut A, Robertson DL.

543 2020. Evolutionary origins of the SARS-CoV-2 sarbecovirus lineage responsible for the

544 COVID-19 pandemic. Nature Microbiology:2020.03.30.015008. DOI: 10.1038/s41564-

545 020-0771-4.

546 Bouvet M, Debarnot C, Imbert I, Selisko B, Snijder EJ. 2010. In Vitro Reconstitution of SARS-

547 Coronavirus mRNA Cap Methylation. PLoS Pathog 6:1000863. DOI:

$548 \quad 10.1371 /$ journal.ppat.1000863.

549 Cagliani R, Forni D, Clerici M, Sironi M. 2020. Computational Inference of Selection

550 Underlying the Evolution of the Novel Coronavirus, Severe Acute Respiratory Syndrome 
551

552

553

554

555

556

557

558

559

560

561

562

563

564

565

566

567

568

569

570

571

572

573

574

575

576

577

578

579

580

581

Coronavirus 2 Downloaded from.jvi.asm.org 1 Journal of Virology 94:411-431. DOI: 10.1128/JVI.00411-20.

Chaw S-M, Tai J-H, Chen S-L, Hsieh C-H, Chang S-Y, Yeh S-H, Yang W-S, Chen P-J, Wang H-Y. 2020. The origin and underlying driving forces of the SARS-CoV-2 outbreak. Journal of biomedical science 27:73. DOI: 10.1186/s12929-020-00665-8.

Cornillez-Ty CT, Liao L, Yates Iii JR, Kuhn P, Buchmeier MJ. 2009. Severe Acute Respiratory Syndrome Coronavirus Nonstructural Protein 2 Interacts with a Host Protein Complex Involved in Mitochondrial Biogenesis and Intracellular Signaling. JOURNAL OF VIROLOGY 83:10314-10318. DOI: 10.1128/JVI.00842-09.

Decroly E, Imbert I, Coutard B, Bouvet M, Selisko B, Alvarez K, Gorbalenya AE, Snijder EJ, Canard B. 2008. Coronavirus Nonstructural Protein 16 Is a Cap-0 Binding Enzyme Possessing (Nucleoside-2'O)-Methyltransferase Activity. Journal of Virology 82:80718084. DOI: $10.1128 /$ jvi.00407-08.

DeLano WL. 2002. Pymol: An open-source molecular graphics tool. :40, 82-92.

Eaaswarkhanth M, Al Madhoun A, Al-Mulla F. 2020. Could the D614G substitution in the SARS-CoV-2 spike (S) protein be associated with higher COVID-19 mortality? International journal of infectious diseases : IJID : official publication of the International Society for Infectious Diseases 96:459-460. DOI: 10.1016/j.ijid.2020.05.071.

Fehr AR, Perlman S. 2015. Coronaviruses: An overview of their replication and pathogenesis. In: Coronaviruses: Methods and Protocols. Springer New York, 1-23. DOI: 10.1007/9781-4939-2438-7_1.

Follis KE, York J, Nunberg JH. 2006. Furin cleavage of the SARS coronavirus spike glycoprotein enhances cell-cell fusion but does not affect virion entry. Virology 350:358369. DOI: 10.1016/j.virol.2006.02.003.

Forni D, Filippi G, Cagliani R, De Gioia L, Pozzoli U, Al-Daghri N, Clerici M, Sironi M. 2015. The heptad repeat region is a major selection target in MERS-CoV and related coronaviruses. Scientific Reports 5:1-10. DOI: 10.1038/srep14480.

Freundt EC, Yu L, Goldsmith CS, Welsh S, Cheng A, Yount B, Liu W, Frieman MB, Buchholz UJ, Screaton GR, Lippincott-Schwartz J, Zaki SR, Xu X-N, Baric RS, Subbarao K, Lenardo MJ. 2010. The Open Reading Frame 3a Protein of Severe Acute Respiratory SyndromeAssociated Coronavirus Promotes Membrane Rearrangement and Cell Death. Journal of 
582

583

584

585

586

587

588

589

590

591

592

593

594

595

596

597

598

599

600

601

602

603

604

605

606

607

608

609

610

611

612

Virology 84:1097-1109. DOI: 10.1128/jvi.01662-09.

Frieman M, Ratia K, Johnston RE, Mesecar AD, Baric RS. 2009. Severe acute respiratory syndrome coronavirus papain-like protease ubiquitin-like domain and catalytic domain regulate antagonism of IRF3 and NF-kappaB signaling. Journal of virology 83:6689-705. DOI: 10.1128/JVI.02220-08.

Fuchs SY. 2012. Ubiquitination-mediated regulation of interferon responses. Growth Factors 30:141-148. DOI: 10.3109/08977194.2012.669382.

Gallagher TM, Buchmeier MJ. 2001. Coronavirus Spike Proteins in Viral Entry and Pathogenesis. Virology 279:371-374. DOI: 10.1006/viro.2000.0757.

Gebhard LG, Filomatori C V., Gamarnik A V. 2011. Functional RNA elements in the dengue virus genome. Viruses 3:1739-1756. DOI: 10.3390/v3091739.

Graham RL, Baric RS. 2010. Recombination, reservoirs, and the modular spike: mechanisms of coronavirus cross-species transmission. Journal of virology 84:3134-46. DOI: 10.1128/JVI.01394-09.

Gruber AR, Lorenz R, Bernhart SH, Neuböck R, Hofacker IL. 2008. The Vienna RNA websuite. Nucleic acids research 36:70-74. DOI: 10.1093/nar/gkn188.

Hagemeijer MC, Monastyrska I, Griffith J, van der Sluijs P, Voortman J, van Bergen en Henegouwen PM, Vonk AM, Rottier PJM, Reggiori F, de Haan CAM. 2014. Membrane rearrangements mediated by coronavirus nonstructural proteins 3 and 4. Virology 458 459:125-135. DOI: 10.1016/j.virol.2014.04.027.

Hagemeijer MC, Ulasli M, Vonk AM, Reggiori F, Rottier PJM, de Haan CAM. 2011. Mobility and Interactions of Coronavirus Nonstructural Protein 4. Journal of Virology 85:4572-4577. DOI: 10.1128/JVI.00042-11.

Hahne F, Ivanek R. 2016. Visualizing genomic data using Gviz and bioconductor. In: Methods in Molecular Biology. Humana Press Inc., 335-351. DOI: 10.1007/978-1-4939-3578-9_16.

Haygood R, Fedrigo O, Hanson B, Yokoyama K-D, Wray GA. 2007. Promoter regions of many neural- and nutrition-related genes have experienced positive selection during human evolution. Nature genetics 39:1140-4. DOI: 10.1038/ng2104.

He X, Lau EHY, Wu P, Deng X, Wang J, Hao X, Lau YC, Wong JY, Guan Y, Tan X, Mo X, Chen Y, Liao B, Chen W, Hu F, Zhang Q, Zhong M, Wu Y, Zhao L, Zhang F, Cowling BJ, Li F, Leung GM. 2020. Temporal dynamics in viral shedding and transmissibility of 
613

614

615

616

617

618

619

620

621

622

623

624

625

626

627

628

629

630

631

632

633

634

635

636

637

638

639

640

641

642

643

COVID-19. Nature Medicine 26:672-675. DOI: 10.1038/s41591-020-0869-5.

Hillen HS, Kokic G, Farnung L, Dienemann C, Tegunov D, Cramer P. 2020. Structure of replicating SARS-CoV-2 polymerase. Nature. DOI: 10.1038/s41586-020-2368-8.

Hoffmann M, Kleine-Weber H, Pöhlmann S. 2020. A Multibasic Cleavage Site in the Spike Protein of SARS-CoV-2 Is Essential for Infection of Human Lung Cells. Molecular Cell 78:779-784.e5. DOI: 10.1016/j.molcel.2020.04.022.

Hon C-C, Lam T-Y, Shi Z-L, Drummond AJ, Yip C-W, Zeng F, Lam P-Y, Chi F, Leung C. 2008. Evidence of the Recombinant Origin of a Bat Severe Acute Respiratory Syndrome (SARS)-Like Coronavirus and Its Implications on the Direct Ancestor of SARS Coronavirus. JOURNAL OF VIROLOGY 82:1819-1826. DOI: 10.1128/JVI.01926-07.

Hu B, Zeng L-P, Yang X-L, Ge X-Y, Zhang W, Li B, Xie J-Z, Shen X-R, Zhang Y-Z, Wang N, Luo D-S, Zheng X-S, Wang M-N, Daszak P, Wang L-F, Cui J, Shi Z-L. 2017. Discovery of a rich gene pool of bat SARS-related coronaviruses provides new insights into the origin of SARS coronavirus. PLOS Pathogens 13:e1006698. DOI: 10.1371/journal.ppat.1006698.

Hubisz MJ, Pollard KS, Siepel A. 2011. PHAST and RPHAST: phylogenetic analysis with space/time models. Briefings in bioinformatics 12:41-51. DOI: 10.1093/bib/bbq072.

Hulswit RJG, de Haan CAM, Bosch BJ. 2016. Coronavirus Spike Protein and Tropism Changes. In: Advances in Virus Research. Academic Press Inc., 29-57. DOI: 10.1016/bs.aivir.2016.08.004.

Huston NC, Wan H, Araujo Tavares R de C, Wilen C, Pyle AM. 2020a. Comprehensive in-vivo secondary structure of the SARS-CoV-2 genome reveals novel regulatory motifs and mechanisms. bioRxiv : the preprint server for biology:1-46. DOI: 10.1101/2020.07.10.197079.

Huston NC, Wan H, Araujo Tavares R de C, Wilen C, Pyle AM. 2020b. Comprehensive in-vivo secondary structure of the SARS-CoV-2 genome reveals novel regulatory motifs and mechanisms. bioRxiv : the preprint server for biology:1-46. DOI: 10.1101/2020.07.10.197079.

Katoh K, Standley DM. 2013. MAFFT Multiple Sequence Alignment Software Version 7: Improvements in Performance and Usability. Molecular Biology and Evolution 30:772-780. DOI: $10.1093 / \mathrm{molbev} / \mathrm{mst} 010$.

Kearse M, Moir R, Wilson A, Stones-Havas S, Cheung M, Sturrock S, Buxton S, Cooper A, 
644

645

646

647

648

649

650

651

652

653

654

655

656

657

658

659

660

661

662

663

664

665

666

667

668

669

670

671

672

673

674

Markowitz S, Duran C, Thierer T, Ashton B, Meintjes P, Drummond A. 2012. Geneious Basic: an integrated and extendable desktop software platform for the organization and analysis of sequence data. Bioinformatics (Oxford, England) 28:1647-9. DOI: 10.1093/bioinformatics/bts199.

Kelley LA, Mezulis S, Yates CM, Wass MN, Sternberg MJE. 2016. The Phyre2 web portal for protein modeling, prediction and analysis. Nature Protocols 10:845-858. DOI: $10.1038 /$ nprot.2015.053.

Kim D, Lee J-Y, Yang J-S, Kim JW, Kim VN, Chang H. 2020. The Architecture of SARS-CoV2 Transcriptome. Cell 181:914-921.e10. DOI: 10.1016/j.cell.2020.04.011.

Korber B, Fischer WM, Gnanakaran S, Yoon H, Theiler J, Abfalterer W, Hengartner N, Giorgi EE, Bhattacharya T, Foley B, Hastie KM, Parker MD, Partridge DG, Evans CM, Freeman TM, de Silva TI, Sheffield COVID-19 Genomics Group, McDanal C, Perez LG, Tang H, Moon-Walker A, Whelan SP, LaBranche CC, Saphire EO, Montefiori DC. 2020. Tracking Changes in SARS-CoV-2 Spike: Evidence that D614G Increases Infectivity of the COVID19 Virus. Cell. DOI: 10.1016/j.cell.2020.06.043.

Kozlov AM, Darriba D, Flouri T, Morel B, Stamatakis A, Wren J. 2019. RAxML-NG: A fast, scalable and user-friendly tool for maximum likelihood phylogenetic inference.

Bioinformatics 35:4453-4455. DOI: 10.1093/bioinformatics/btz305.

Lam TT-Y, Jia N, Zhang Y-W, Shum MH-H, Jiang J-F, Zhu H-C, Tong Y-G, Shi Y-X, Ni X-B, Liao Y-S, Li W-J, Jiang B-G, Wei W, Yuan T-T, Zheng K, Cui X-M, Li J, Pei G-Q, Qiang X, Cheung WY-M, Li L-F, Sun F-F, Qin S, Huang J-C, Leung GM, Holmes EC, Hu Y-L, Guan Y, Cao W-C. 2020. Identifying SARS-CoV-2-related coronaviruses in Malayan pangolins. Nature 583:282-285. DOI: 10.1038/s41586-020-2169-0.

Lau SKP, Feng Y, Chen H, Luk HKH, Yang W-H, Li KSM, Zhang Y-Z, Huang Y, Song Z-Z, Chow W-N, Fan RYY, Ahmed SS, Yeung HC, Lam CSF, Cai J-P, Wong SSY, Chan JFW, Yuen K-Y, Zhang H-L, Woo PCY. 2015. Severe Acute Respiratory Syndrome (SARS) Coronavirus ORF8 Protein Is Acquired from SARS-Related Coronavirus from Greater Horseshoe Bats through Recombination. Journal of Virology 89:10532-10547. DOI: 10.1128/jvi.01048-15.

Li X, Giorgi EE, Marichannegowda MH, Foley B, Xiao C, Kong X-P, Chen Y, Gnanakaran S, Korber B, Gao F. 2020a. Emergence of SARS-CoV-2 through recombination and strong 
675 purifying selection. Science Advances 6:eabb9153. DOI: 10.1126/sciadv.abb9153.

676 Li Y, Yang X, Wang N, Wang H, Yin B, Yang X, Jiang W. 2020b. The divergence between

677 SARS-CoV-2 and RaTG13 might be overestimated due to the extensive RNA modification.

678 Future Virology:fvl-2020-0066. DOI: 10.2217/fvl-2020-0066.

679 Liu P, Chen W, Chen J-P. 2019. Viral Metagenomics Revealed Sendai Virus and Coronavirus

680 Infection of Malayan Pangolins (Manis javanica). Viruses 11:979. DOI:

$681 \quad 10.3390 / \mathrm{v} 11110979$.

682 Lorenz R, Bernhart SH, Höner zu Siederdissen C, Tafer H, Flamm C, Stadler PF, Hofacker IL.

683 2011. ViennaRNA Package 2.0. Algorithms for Molecular Biology 6:26. DOI:

$684 \quad 10.1186 / 1748-7188-6-26$.

685 Lu W, Zheng BJ, Xu K, Schwarz W, Du L, Wong CKL, Chen J, Duan S, Deubel V, Sun B.

686 2006. Severe acute respiratory syndrome-associated coronavirus 3a protein forms an ion

687 channel and modulates virus release. Proceedings of the National Academy of Sciences of

688 the United States of America 103:12540-12545. DOI: 10.1073/pnas.0605402103.

689 M de Haan CA, Stadler K, Godeke G-J, Jan Bosch B, M Rottier PJ. 2004. Cleavage Inhibition of 690 the Murine Coronavirus Spike Protein by a Furin-Like Enzyme Affects Cell-Cell but Not 691 Virus-Cell Fusion Downloaded from. JOURNAL OF VIROLOGY 78:6048-6054. DOI:

$692 \quad 10.1128 / J V I .78 .11 .6048-6054.2004$.

693 MacFadden A, Òdonoghue Z, Silva PAGC, Chapman EG, Olsthoorn RC, Sterken MG, Pijlman

694 GP, Bredenbeek PJ, Kieft JS. 2018. Mechanism and structural diversity of exoribonuclease-

695 resistant RNA structures in flaviviral RNAs. Nature Communications 9:1-11. DOI:

$696 \quad 10.1038 / \mathrm{s} 41467-017-02604-\mathrm{y}$.

697 Madhugiri R, Fricke M, Marz M, Ziebuhr J. 2016. Coronavirus cis-Acting RNA Elements. In:

698 Advances in Virus Research. Academic Press Inc., 127-163. DOI:

$699 \quad$ 10.1016/bs.aivir.2016.08.007.

700 Mathews DH. 2005. Predicting a set of minimal free energy RNA secondary structures common 701 to two sequences. Bioinformatics 21:2246-2253. DOI: 10.1093/bioinformatics/bti349.

702 Matthews K, Schäfer A, Pham A, Frieman M. 2014. The SARS coronavirus papain like protease 703 can inhibit IRF3 at a post activation step that requires deubiquitination activity. Virology 704 Journal 11:209. DOI: 10.1186/s12985-014-0209-9.

705 Menachery VD, Debbink K, Baric RS. 2014. Coronavirus non-structural protein 16: Evasion, 
706

707

708

709

710

711

712

713

714

715

716

717

718

719

720

721

722

723

724

725

726

727

728

729

730

731

732

733

734

735

736

attenuation, and possible treatments. Virus Research 194:191-199. DOI: 10.1016/j.virusres.2014.09.009.

Minakshi R, Padhan K, Rani M, Khan N, Ahmad F, Jameel S. 2009. The SARS Coronavirus 3a protein causes endoplasmic reticulum stress and induces ligand-independent downregulation of the type 1 interferon receptor. PloS one 4:e8342. DOI: 10.1371/journal.pone.0008342.

Morens DM, Breman JG, Calisher CH, Doherty PC, Hahn BH, Keusch GT, Kramer LD, LeDuc JW, Monath TP, Taubenberger JK. 2020. The Origin of COVID-19 and Why It Matters. The American journal of tropical medicine and hygiene 103:955-959. DOI: 10.4269/ajtmh.20-0849.

Nelemans T, Kikkert M. 2019. Viral innate immune evasion and the pathogenesis of emerging RNA virus infections. Viruses 11. DOI: 10.3390/v11100961.

Oostra M, Hagemeijer MC, van Gent M, Bekker CPJ, te Lintelo EG, Rottier PJM, de Haan CAM. 2008. Topology and Membrane Anchoring of the Coronavirus Replication Complex: Not All Hydrophobic Domains of nsp3 and nsp6 Are Membrane Spanning. Journal of Virology 82:12392-12405. DOI: 10.1128/jvi.01219-08.

Pachetti M, Marini B, Benedetti F, Giudici F, Mauro E, Storici P, Masciovecchio C, Angeletti S, Ciccozzi M, Gallo RC, Zella D, Ippodrino R. 2020. Emerging SARS-CoV-2 mutation hot spots include a novel RNA-dependent-RNA polymerase variant. Journal of Translational Medicine 18:1-9. DOI: 10.1186/s12967-020-02344-6.

Pan J, Qian X, Lattmann S, El Sahili A, Yeo TH, Jia H, Cressey T, Ludeke B, Noton S, Kalocsay M, Fearns R, Lescar J. 2020. Structure of the human metapneumovirus polymerase phosphoprotein complex. Nature 577:275-279. DOI: 10.1038/s41586-019-1759-1.

Peiris JSM, Chu CM, Cheng VCC, Chan KS, Hung IFN, Poon LLM, Law KI, Tang BSF, Hon TYW, Chan CS, Chan KH, Ng JSC, Zheng BJ, Ng WL, Lai RWM, Guan Y, Yuen KY. 2003. Clinical progression and viral load in a community outbreak of coronavirusassociated SARS pneumonia: A prospective study. Lancet 361:1767-1772. DOI: 10.1016/S0140-6736(03)13412-5.

Pirakitikulr N, Kohlway A, Lindenbach BD, Pyle AM. 2016. The Coding Region of the HCV Genome Contains a Network of Regulatory RNA Structures. Molecular cell 62:111-20. DOI: 10.1016/j.molcel.2016.01.024. 
737 Pitzer VE, Leung GM, Lipsitch M. 2007. Estimating variability in the transmission of severe 738 acute respiratory syndrome to household contacts in Hong Kong, China. American Journal 739 of Epidemiology 166:355-363. DOI: 10.1093/aje/kwm082.

740

741

742

743

744

745

746

747

748

749

750

751

752

753

754

755

756

757

758

759

760

761

762

763

764

765

766

767

Pond SLK, Frost SDW, Muse S V. 2005. HyPhy: hypothesis testing using phylogenies.

Bioinformatics (Oxford, England) 21:676-9. DOI: 10.1093/bioinformatics/bti079.

Pond SLK, Poon AFY, Velazquez R, Weaver S, Hepler NL, Murrell B, Shank SD, Magalis BR, Bouvier D, Nekrutenko A, Wisotsky S, Spielman SJ, Frost SDW, Muse S V. 2020. HyPhy 2.5-A Customizable Platform for Evolutionary Hypothesis Testing Using Phylogenies. Molecular biology and evolution 37:295-299. DOI: 10.1093/molbev/msz197.

Rangan R, Zheludev IN, Hagey RJ, Pham EA, Wayment-Steele HK, Glenn JS, Das R. 2020. RNA genome conservation and secondary structure in SARS-CoV-2 and SARS-related viruses: a first look. RNA (New York, N.Y.) 26:937-959. DOI: 10.1261/rna.076141.120.

Sanders W, Fritch EJ, Madden EA, Graham RL, Vincent HA, Heise MT, Baric RS, Moorman NJ. 2020. Comparative analysis of coronavirus genomic RNA structure reveals conservation in SARS-like coronaviruses. bioRxiv : the preprint server for biology. DOI: 10.1101/2020.06.15.153197.

Siepel A, Bejerano G, Pedersen JS, Hinrichs AS, Hou M, Rosenbloom K, Clawson H, Spieth J, Hillier LDW, Richards S, Weinstock GM, Wilson RK, Gibbs RA, Kent WJ, Miller W, Haussler D. 2005. Evolutionarily conserved elements in vertebrate, insect, worm, and yeast genomes. Genome Research 15:1034-1050. DOI: 10.1101/gr.3715005.

Snijder EJ, Decroly E, Ziebuhr J. 2016. The Nonstructural Proteins Directing Coronavirus RNA Synthesis and Processing. In: Advances in Virus Research. Academic Press Inc., 59-126. DOI: 10.1016/bs.aivir.2016.08.008.

Tan Y-J, Tham P-Y, Chan DZL, Chou C-F, Shen S, Fielding BC, Tan THP, Lim SG, Hong W. 2005. The Severe Acute Respiratory Syndrome Coronavirus 3a Protein Up-Regulates Expression of Fibrinogen in Lung Epithelial Cells. Journal of Virology 79:10083-10087. DOI: 10.1128/jvi.79.15.10083-10087.2005.

Tang X, Wu C, Li X, Song Y, Yao X, Wu X, Duan Y, Zhang H, Wang Y, Qian Z, Cui J, Lu J. 2020. On the origin and continuing evolution of SARS-CoV-2. National Science Review 7:1012-1023. DOI: 10.1093/nsr/nwaa036.

Tortorici MA, Veesler D. 2019. Structural insights into coronavirus entry. Advances in virus 
768

769

770

771

772

773

774

775

776

777

778

779

780

781

782

783

784

785

786

787

788

789

790

791

792

793

794

795

796

797

798

research 105:93-116. DOI: 10.1016/bs.aivir.2019.08.002.

Toyoshima Y, Nemoto K, Matsumoto S, Nakamura Y, Kiyotani K. 2020. SARS-CoV-2 genomic variations associated with mortality rate of COVID-19. Journal of Human Genetics:1-8. DOI: $10.1038 / \mathrm{s} 10038-020-0808-9$.

Tsuchida T, Kawai T, Akira S. 2009. Inhibition of IRF3-dependent antiviral responses by cellular and viral proteins. Cell Research 19:3-4. DOI: 10.1038/cr.2009.1.

Velazquez-Salinas L, Zarate S, Eberl S, Gladue DP, Novella I, Borca M V. 2020. Positive selection of ORF3a and ORF8 genes drives the evolution of SARS-CoV-2 during the 2020 COVID-19 pandemic. bioRxiv:2020.04.10.035964. DOI: 10.1101/2020.04.10.035964.

Wang Y, Liu M, Gao J. 2020. Enhanced receptor binding of SARS-CoV-2 through networks of hydrogen-bonding and hydrophobic interactions. Proceedings of the National Academy of Sciences of the United States of America 117:13967-13974. DOI: 10.1073/pnas.2008209117.

Wang Q, Zhang Y, Wu L, Niu S, Song C, Zhang Z, Lu G, Qiao C, Hu Y, Yuen KY, Wang Q, Zhou H, Yan J, Qi J. 2020. Structural and Functional Basis of SARS-CoV-2 Entry by Using Human ACE2. Cell 181:894-904.e9. DOI: 10.1016/j.cell.2020.03.045.

Watanabe Y, Bowden TA, Wilson IA, Crispin M. 2019. Exploitation of glycosylation in enveloped virus pathobiology. Biochimica et biophysica acta. General subjects 1863:14801497. DOI: 10.1016/j.bbagen.2019.05.012.

Wong WSW, Nielsen R. 2004. Detecting selection in noncoding regions of nucleotide sequences. Genetics 167:949-58. DOI: 10.1534/genetics.102.010959.

Wrapp D, Wang N, Corbett KS, Goldsmith JA, Hsieh C-L, Abiona O, Graham BS, McLellan JS. 2020. Cryo-EM structure of the 2019-nCoV spike in the prefusion conformation. Science 367:1260-1263. DOI: 10.1126/science.abb2507.

Yang T-J, Chang Y-C, Ko T-P, Draczkowski P, Chien Y-C, Chang Y-C, Wu K-P, Khoo K-H, Chang H-W, Hsu S-TD. 2020. Cryo-EM analysis of a feline coronavirus spike protein reveals a unique structure and camouflaging glycans. Proceedings of the National Academy of Sciences 117:1438-1446. DOI: 10.1073/pnas.1908898117.

Ye Y, Godzik A. 2004. FATCAT: a web server for flexible structure comparison and structure similarity searching. Nucleic Acids Research 32:W582-W585. DOI: 10.1093/nar/gkh430.

Yue Y, Nabar NR, Shi CS, Kamenyeva O, Xiao X, Hwang IY, Wang M, Kehrl JH. 2018. SARS- 
799 Coronavirus Open Reading Frame-3a drives multimodal necrotic cell death. Cell Death and 800 Disease 9:1-15. DOI: 10.1038/s41419-018-0917-y.

801 Ziv O, Price J, Shalamova L, Kamenova T, Goodfellow I, Weber F, Miska EA. 2020. The short802 and long-range RNA-RNA Interactome of SARS-CoV-2 Co-first authors.

803 bioRxiv:2020.07.19.211110. DOI: 10.1101/2020.07.19.211110.

804 Züst R, Cervantes-Barragan L, Habjan M, Maier R, Neuman BW, Ziebuhr J, Szretter KJ, Baker 805 SC, Barchet W, Diamond MS, Siddell SG, Ludewig B, Thiel V. 2011. Ribose 2'-O806 methylation provides a molecular signature for the distinction of self and non-self mRNA 807 dependent on the RNA sensor Mda5. Nature immunology 12:137-43. DOI:

$808 \quad 10.1038 /$ ni. 1979.

809 


\section{Table $\mathbf{1}$ (on next page)}

Coronavirus Accessions.

NCBI accessions of the Coronavirus sequences used in this study 
2 Table 1. Coronavirus Accessions.

\begin{tabular}{|c|c|c|c|}
\hline Coronavirus Species & Name Used & $\begin{array}{l}\text { NCBI } \\
\text { Reference } \\
\text { Sequence }\end{array}$ & Link \\
\hline $\begin{array}{l}\text { Severe acute } \\
\text { respiratory syndrome } \\
\text { coronavirus } 2 \text { isolate } \\
\text { Wuhan-Hu-1, } \\
\text { complete genome }\end{array}$ & SARS-CoV-2 & NC_045512.2 & $\begin{array}{l}\text { https://www.ncbi.nlm.nih.gov/nuccore/N } \\
\text { C } 045512\end{array}$ \\
\hline $\begin{array}{l}\text { Bat coronavirus } \\
\text { RaTG13, complete } \\
\text { genome }\end{array}$ & $\begin{array}{l}\text { Bat-CoV- } \\
\text { RaTG13 }\end{array}$ & MN996532.1 & $\begin{array}{l}\text { https://www.ncbi.nlm.nih.gov/nuccore/M } \\
\text { N996532.1 }\end{array}$ \\
\hline $\begin{array}{l}\text { Pangolin coronavirus } \\
\text { isolate MP789, } \\
\text { complete genome }\end{array}$ & Pan-CoV-GD & MT121216.1 & $\begin{array}{l}\text { https://www.ncbi.nlm.nih.gov/nuccore/M } \\
\text { T121216.1 }\end{array}$ \\
\hline $\begin{array}{l}\text { Pangolin coronavirus } \\
\text { isolate PCoV_GX- } \\
\text { P4L, complete } \\
\text { genome }\end{array}$ & Pan-CoV-GX & MT040333.1 & $\begin{array}{l}\text { https://www.ncbi.nlm.nih.gov/nuccore/M } \\
\text { T040333.1 }\end{array}$ \\
\hline $\begin{array}{l}\text { Rhinolophus affinis } \\
\text { coronavirus isolate } \\
\text { LYRa11, complete } \\
\text { genome }\end{array}$ & $\begin{array}{l}\text { Bat-CoV- } \\
\text { LYRa11 }\end{array}$ & KF569996.1 & $\begin{array}{l}\text { https://www.ncbi.nlm.nih.gov/nuccore/K } \\
\text { F569996.1 }\end{array}$ \\
\hline $\begin{array}{l}\text { SARS coronavirus } \\
\text { Tor2, complete } \\
\text { genome } \\
\text { NCBI Reference }\end{array}$ & SARS-CoV & NC_004718.3 & $\begin{array}{l}\text { https://www.ncbi.nlm.nih.gov/nuccore/3 } \\
\underline{0271926}\end{array}$ \\
\hline $\begin{array}{l}\text { Bat coronavirus } \\
\text { BM48-31/BGR/2008, } \\
\text { complete genome } \\
\text { NCBI Reference }\end{array}$ & Bat-CoV-BM48 & NC_014470.1 & $\begin{array}{l}\text { https://www.ncbi.nlm.nih.gov/nuccore/N } \\
\text { C_ } 014470.1\end{array}$ \\
\hline
\end{tabular}

3 


\section{Figure 1}

Distribution of evolutionary rate and positive selection across multiple species of coronaviruses of the Sarbecovirus family

(A) Distribution of the evolutionary ratio, $\zeta$, along multiple viral genome alignments. Red dots imply significant values of zeta from the adaptiPhy test, black dots represent neutral evolution or purifying selection in the foreground branch. (B) Visualization of selection within Spike protein among species. Dark red symbolizes windows where $\zeta$ is higher than 4 , red is a significant $\zeta$ and gray, neutral or purifying selection in the foreground branch. RBD $=$ receptor binding domain. (C) Tertiary structure of Spike protein depicting the location positive selection (left) and amino acid substitutions (right) in SARS-CoV-2 and SARS-CoV. 


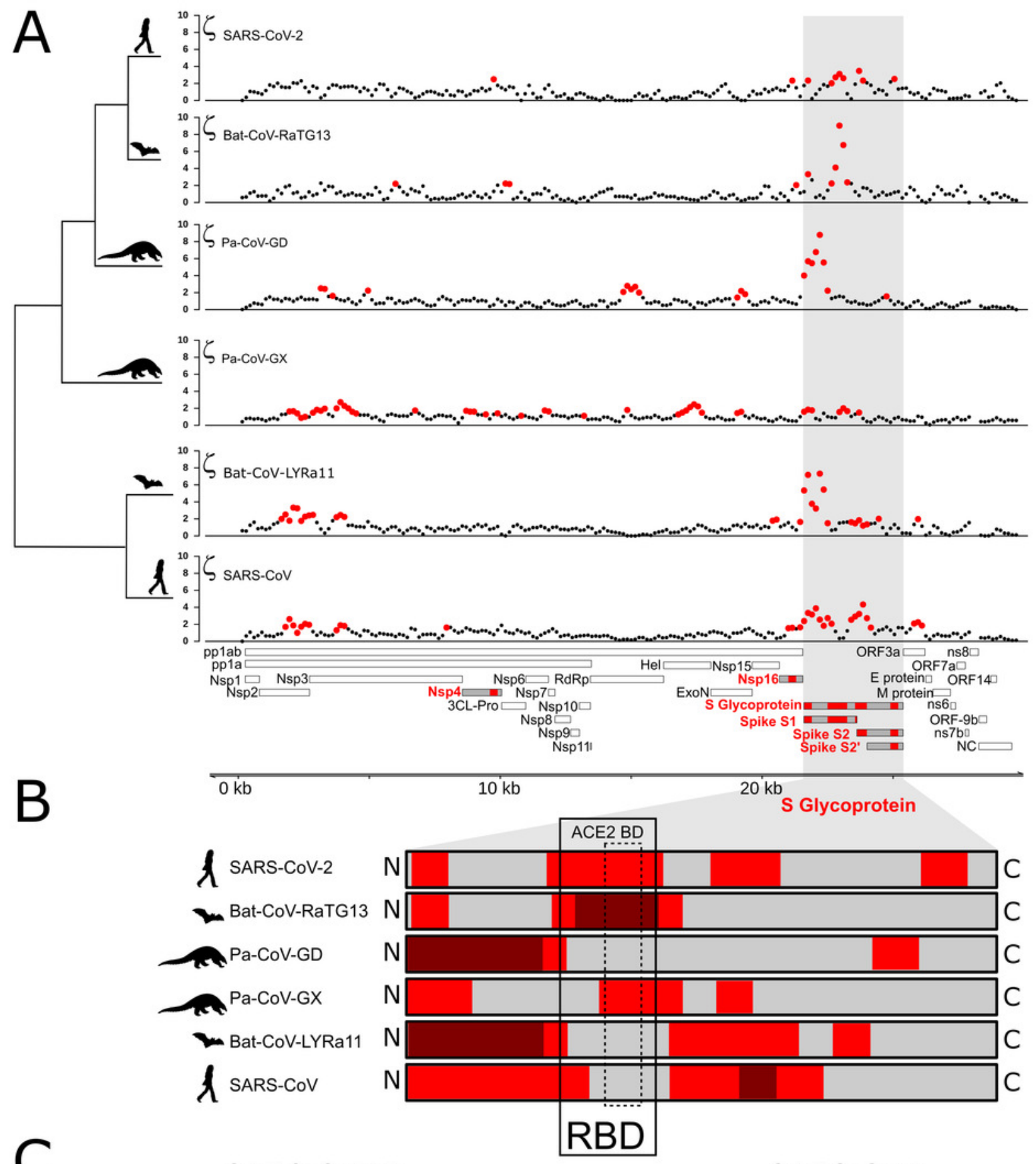

SARS-CoV-2

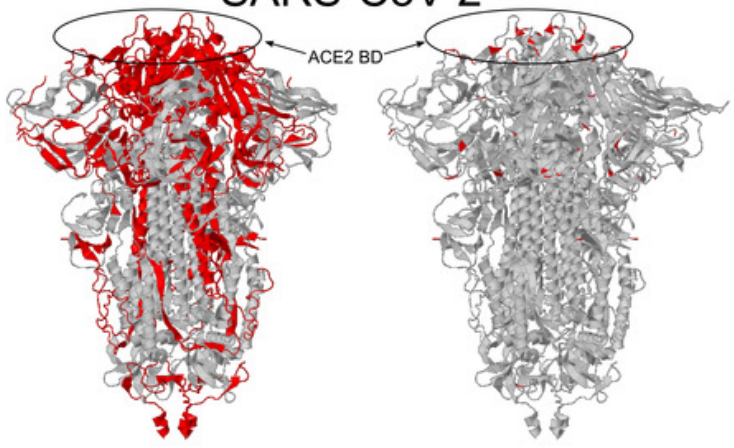

SARS-CoV

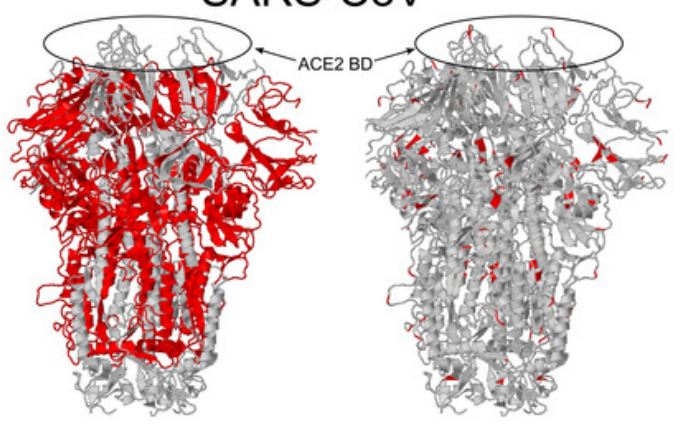




\section{Figure 2}

Distribution of positive selection, phastcons conservation, and polymorphic variation across the SARS-CoV-2 genome.

(A) Evolutionary rate (ろ) with sites under significant branch specific selection as red dots. (B) Panel depicting conservation values (PhastCons) with highly conserved windows (PhastCons $>0.9$ ) as blue dots over the dashed line along the SARS-CoV-2 genome. (C) Alternative allele frequency for 5,000 high quality genomes available in NCBI. Dotted line represents an arbitrary threshold of 0.6 and SNPs in strong linkage disequilibrium are highlighted with arrowheads under black bars. (D) Allele density in windows of $500 \mathrm{bp}$ with a step of $150 \mathrm{bp}$. Red boxes in $\mathrm{B}$ and $\mathrm{C}$ symbolize regions under positive selection, while blue boxes represent high conservation. (E) Annotations for all the mature proteins known to be expressed in SARS-COV-2. 
A

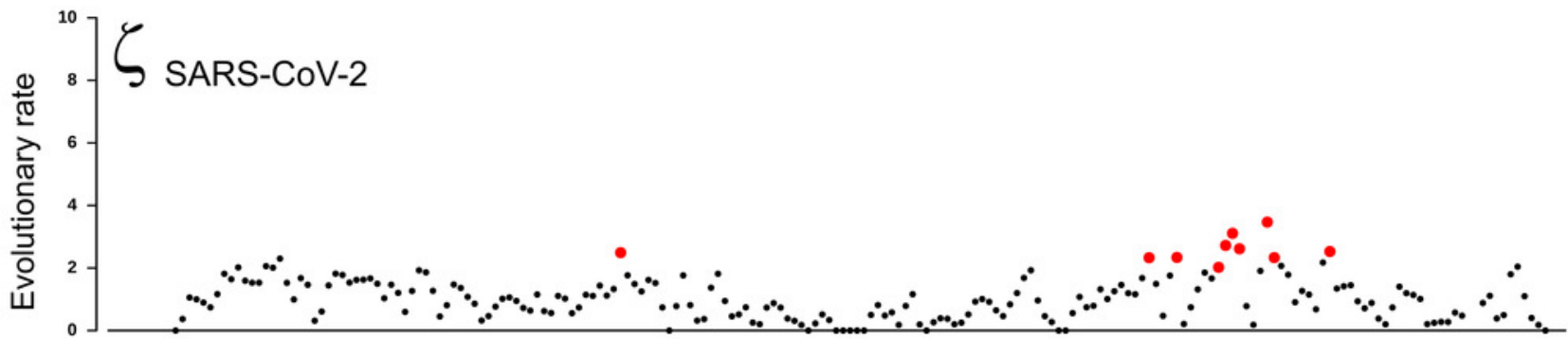

B

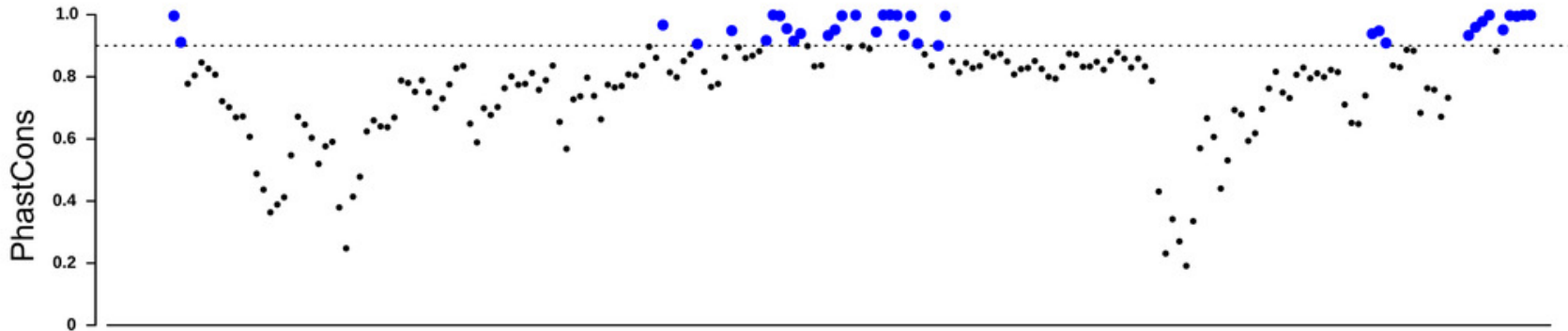

C

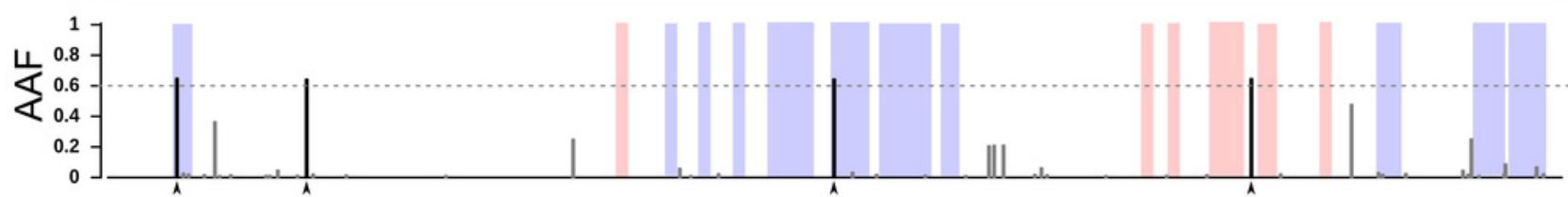

D

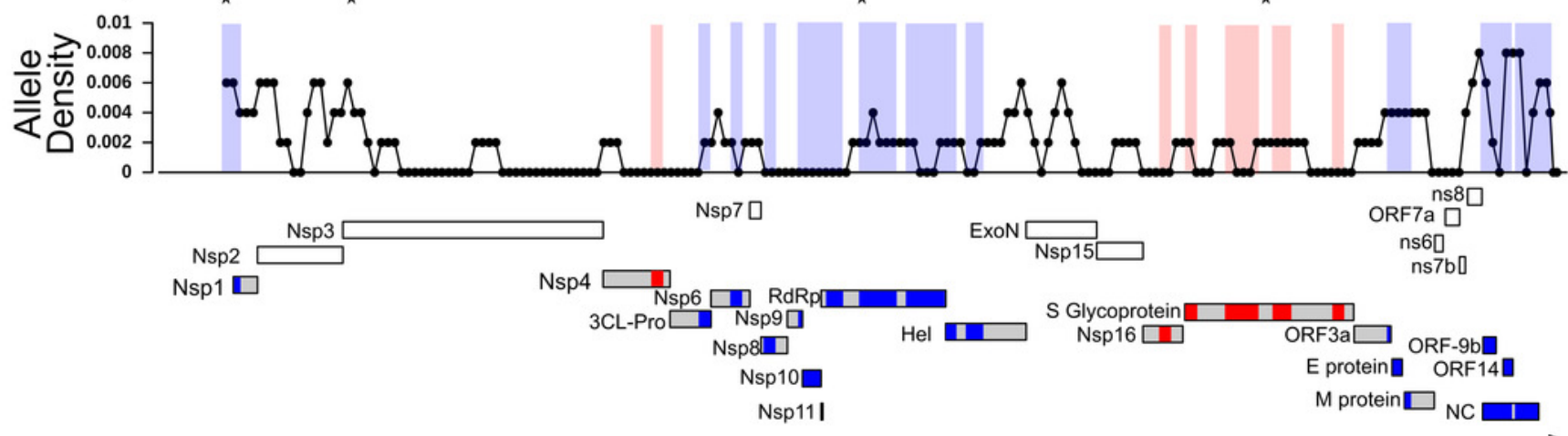

$0 \mathrm{~kb}$

$10 \mathrm{~kb}$

$20 \mathrm{~kb}$ 
Figure 3

RNA and Protein sequences of Spike, Nsp4 and Nsp16.

Each panel from A-C shows selected RNA (top) and protein sequences (bottom) scoring high for positive selection in the SARS-CoV-2 branch and other branches (highlighted in red).

Changes respect to SARS-CoV-2 are highlighted in different colors.

Spike

A
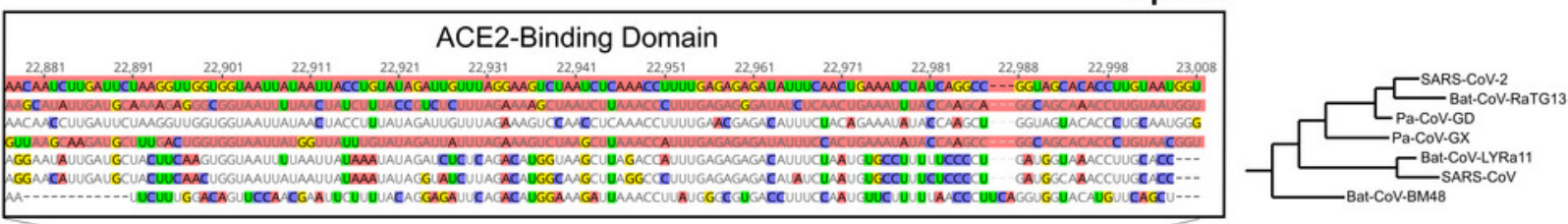

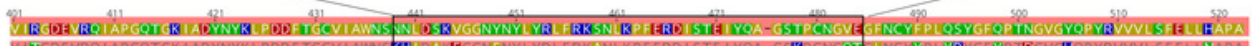

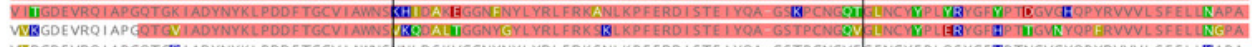

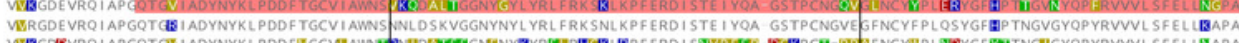

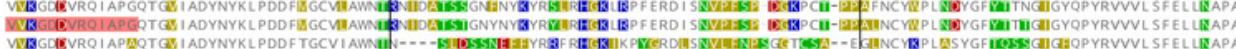
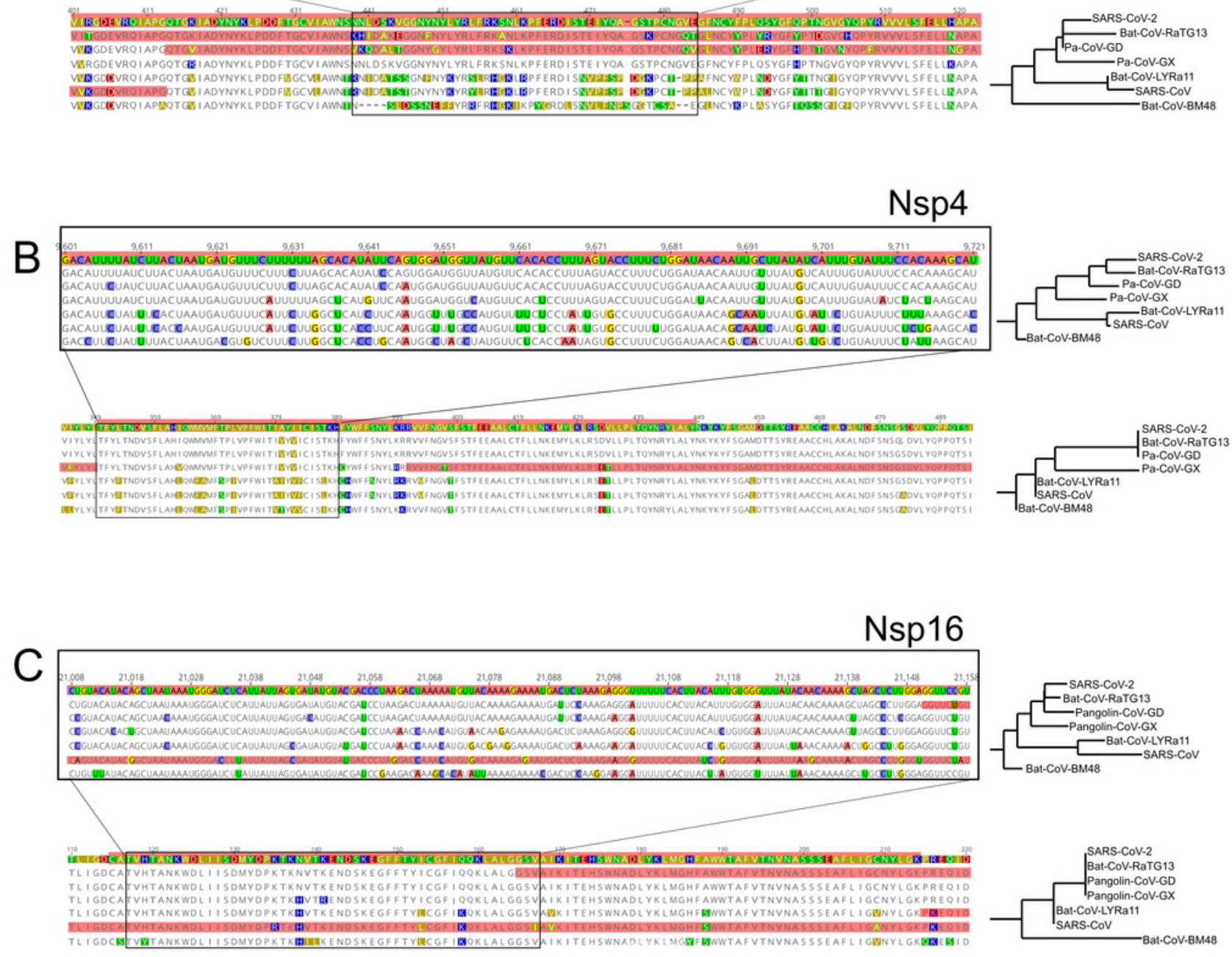


\section{Figure 4}

Regions of coronavirus genomes that violate the species tree

The species tree topology is shown on the left. (A)-(L) Tree topologies that were different from the expected topology. (M) Coronavirus genome track where the regions scoring high for positive selection in SARS-CoV-2 are highlighted in orange, regions with unexpected tree topologies highlighted in dark gray. 


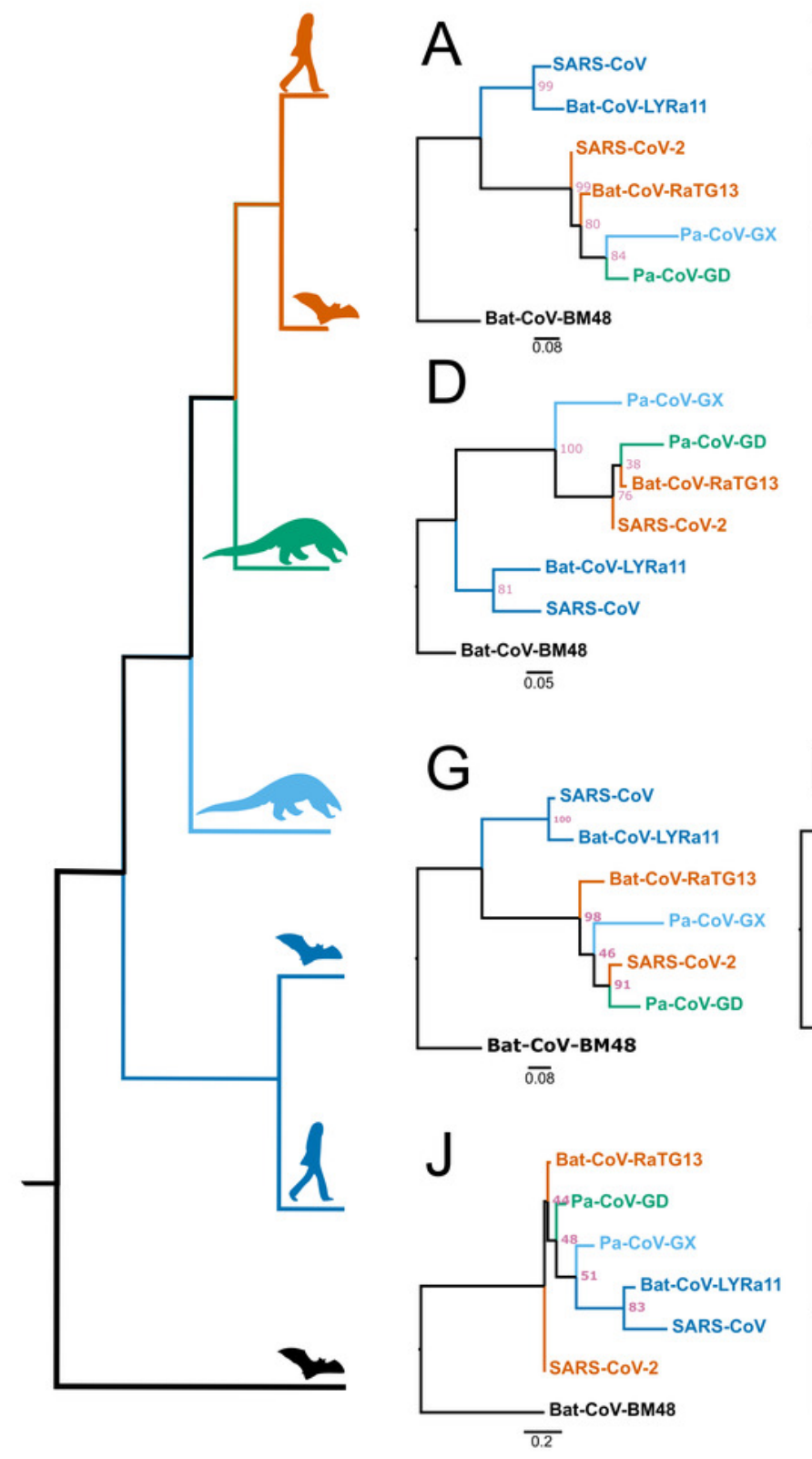

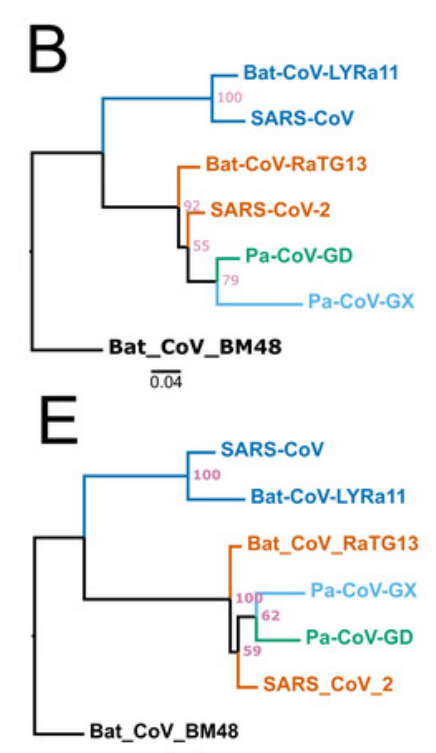

$\overline{0.03}$

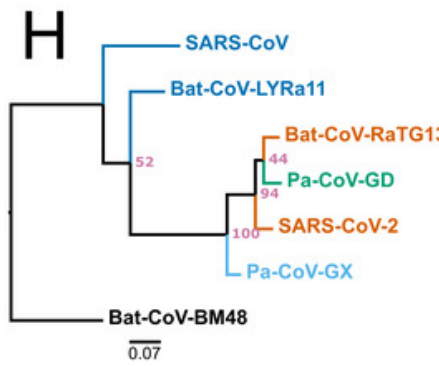

$\overline{0.07}$

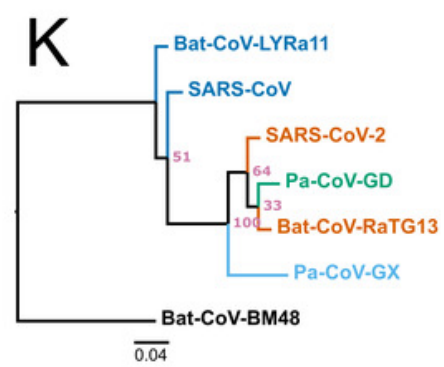

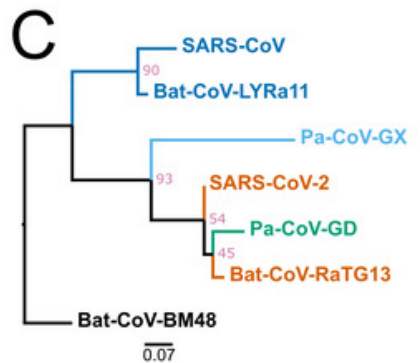

F

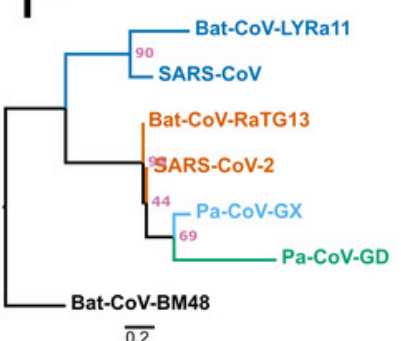

$\overline{0.2}$
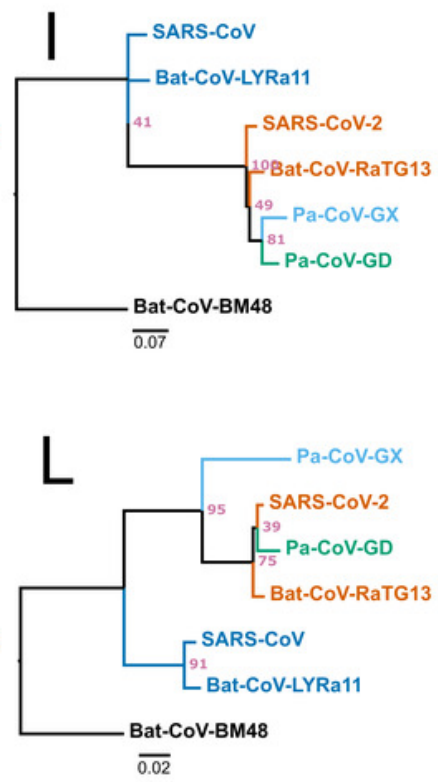

M

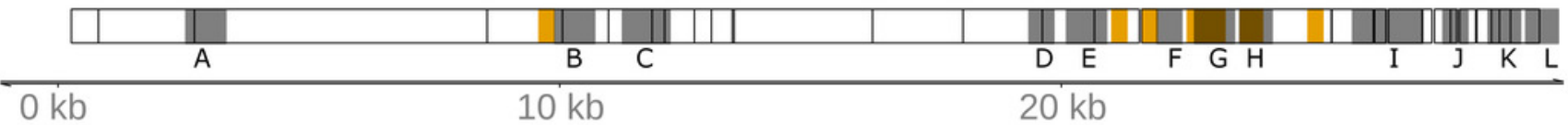

